\title{
Circulating MicroRNA
}

National Cancer Institute

\section{Source}

National Cancer Institute. Circulating MicroRNA. NCI Thesaurus. Code C123153.

MicroRNA found in the peripheral blood. 